\title{
Evaluation of the neurological safety of epidurally- administered pregabalin in rats
}

\author{
Jeong Rim Lee ${ }^{1}$, Pyung-Bok Lee ${ }^{2}$, Gheeyoung Choe ${ }^{3}$, Sang Chul Lee ${ }^{2}$, Hyo Min Lee ${ }^{4}$ Eunjung Kim², \\ and Yong Chul Kim² \\ ${ }^{1}$ Department of Anesthesiology and Pain Medicine, Anesthesia and Pain Research Institute, Yonsei University College of Medicine, \\ Departments of ${ }^{2}$ Anesthesiology and Pain Medicine, ${ }^{3}$ Pathology, Seoul National University College of Medicine, Seoul, ${ }^{4}$ Department \\ of Anesthesiology and Pain Medicine, Pyeongchon Sacred Heart Hospital, Hallym University College of Medicine, Anyang, Korea
}

Background: The primary site of action of pregabalin, i.e. the $\alpha-2-\delta$ subunit of the voltage-dependent calcium channel, is located at the dorsal root ganglion and dorsal horn of the spinal cord. Therefore, the epidural administration of pregabalin could have advantages over oral administration. However, the possibility of its neurotoxicity should be excluded before any attempt at epidural administration. We evaluated the neuronal safety of epidurallyadministered pregabalin by observing the sensory/motor changes and examining the histopathology of spinal cord in rats.

Methods: Sixty rats of $180-230 \mathrm{~g}$ were divided into three groups; $3 \mathrm{mg}$ of pregabalin dissolved in $0.3 \mathrm{ml}$ saline (group $\mathrm{P}, \mathrm{n}=20$ ), $0.3 \mathrm{ml} 40 \%$ alcohol (group $\mathrm{A}, \mathrm{n}=20$ ), or $0.3 \mathrm{ml}$ normal saline (group $\mathrm{N}, \mathrm{n}=20$ ) was administered epidurally to the rats in each group. Pinch-toe test, motor function evaluation, and histopathologic examination of vacuolation, chromatolysis, meningeal inflammation, and neuritis were performed at the 1st, 3rd, 7th, and 21st day after each epidural administration.

Results: All rats enrolled in group P, like those in group N, showed neither sensory/motor dysfunction nor any histopathological abnormality over the 3-week observation period. In contrast, in group A, $80 \%$ of the rats showed abnormal response to the pinch-toe test and all rats showed decreased motor function during the entire evaluation period. In addition, all histopathologic findings of neurotoxicity were observed exclusively in group A.

Conclusions: The epidurally administered pregabalin (about $15 \mathrm{mg} / \mathrm{kg}$ ) did not cause any neurotoxic evidence, in terms of both sensory/motor function evaluation and histopathological examination in rats. (Korean J Anesthesiol 2012; 62: 57-65)

Key Words: Epidural injection, Neurotoxicity, Pregabalin.

Received: March 17, 2011. Revised: June 27, 2011. Accepted: July 11, 2011.

Corresponding author: Yong Chul Kim, M.D., Department of Anesthesiology and Pain Medicine, Seoul National University College of Medicine, 101, Daehak-no, Jongno-gu, Seoul 110-744, Korea. Tel: 82-2-2072-2467, Fax: 82-2-747-5639, E-mail: pain@snu.ac.kr

(c) This is an open-access article distributed under the terms of the Creative Commons Attribution Non-Commercial License (http:// creativecommons.org/licenses/by-nc/3.0/), which permits unrestricted non-commercial use, distribution, and reproduction in any medium, provided the original work is properly cited. 


\section{Introduction}

Pregabalin (S-3-aminomethyl-5-methylhexanoic acid, Lyrica $^{\circledR}$, Pfizer, NY) is used for ameliorating either neuropathic or inflammatory pain [1-3]. Its analgesic effects act through the $\alpha-2-\delta$ subunit of high voltage-activated $\mathrm{N}$-type calcium channel, which is distributed primarily in the dorsal horn of the spinal cord and the presynaptic neuron of the dorsal root ganglion [4-7]. It has been shown that, when administered epidurally, ziconotide (i.e. one of calcium channel blockers) had better analgesic effects, reduced narcotic dose, and improved quality-of-life [4-8]. In addition, in animal studies, neuraxial administration of gabapentin was therapeutically effective, while reducing the dose, in comparison with other administration routes [5,9-12]. Based on these results, epidurally-administered pregabalin could affect either the dorsal horn or the dorsal root ganglion directly and rapidly, and by doing so might augment efficacy, reduce the dosage, and minimize side effects.

Although oral pregabalin is used safely, direct intrathecal or epidural administration causes the direct contact of the nerve with drugs; the possibility of other unknown side-effects should be kept in mind, if administration route is changed [13,14]. With regard to this concern, Hassenbusch et al. [14] suggested the minimal standard that should be met prior to clinical uses. This standard recommends that in preclinical studies on the neuraxial administration of drugs, experiments on both neurotoxicity and side effects are 'essential', whereas other experiments, such as action mechanisms, pharmacodynamics or effectiveness, are 'recommended'. If neuraxial pregabalin induces neurotoxicity by direct contact with the nerves, it could never be used in clinical practice, regardless of its effectiveness. Therefore, pertinent neurological safety must be provided in advance.

The purpose of this study was to provide the neurological safety of the epidural administration of pregabalin and to establish the basis for further animal and clinical studies; accordingly, pregabalin was administered to the epidural space of rats and the neurotoxicity elicited via this route was evaluated by both behavior observation and histopathological examination.

\section{Materials and Methods}

The experimental protocol was approved by the Institutional Animal Care and Use Committee in the Clinical Research Institute of our university hospital.

Sixty male Sprague-Dawley rats of 180-230 g were used. Prior to the study, all rats had free access to food and water and were individually housed, under 12-h light/dark cycle, for 1 week.

Pregabalin was provided by the manufacturer (Pfizer, NY) as white crystalline powder without any additives, and epidural catheters were prepared by cutting polyethylene catheters, which had an outer diameter of $0.61 \mathrm{~mm}$ (PE-10: Natsume, Japan) and approximately $15 \mathrm{~cm}$ in length, with knotting in the $3 \mathrm{~cm}$ area.

For epidural catheterization, each rat was anesthetized using spontaneous inhalation of $2-3 \%$ sevoflurane in oxygen, through a loose-fitting facial mask. After depilation and disinfection of the back area, epidural catheterization was performed according to the previously used technique for small animals [15-18], with some modification; thus, a $2-3 \mathrm{~cm}$ midline incision was made at the L5-L6 intervertebral space for exposure of the ligamentum flavum, and a small hole was made with a micro-scissor at the center of the ligamentum flavum. The prepared epidural catheter was inserted through the hole and gently advanced about $3 \mathrm{~cm}$ cephalad, for the catheter tip to be placed in the L1 region. The catheter entry site was sealed with $\alpha$-cyanoacetylate (Aron-Alpha ${ }^{\circledR}$, Toagosei, Japan), and the wound was sutured layer by layer, after irrigation with saline. To confirm correct epidural placement of the catheter, $0.15 \mathrm{ml}$ of $2 \%$ lidocaine was injected through the catheter after recovery from anesthesia; if the rat showed transient hind-limb paralysis, the catheter was regarded to be positioned in the epidural space. If sudden respiratory arrest was observed during lidocaine injection, the test solution was regarded to be injected either intrathecally or intravenously, and such cases were excluded from the study. In addition, the rats with aspiration of either blood or cerebrospinal fluid through the catheter, with leakage of drugs at the insertion area, or without any paralytic symptom in the hind limbs after lidocaine injection, were also excluded. After confirming correct epidural catheter placement, we observed the gait, spinal deformity, and behavioral abnormalities for 3 days. If the rats showed no abnormal findings during the 3-day observation period, they were included in this study.

The rats were divided into 3 groups, according to the injected solution; group A was injected with $40 \%$ alcohol, group $\mathrm{N}$ was injected with saline, and group $\mathrm{P}$ was injected with $0.3 \mathrm{mg}$ of pregabalin. The total injected volume was $0.3 \mathrm{ml}$, excluding the volume within the catheter. The study drugs were injected slowly under general anesthesia. After injection, the rats were individually housed under a 12-h light/dark cycle.

Acute toxicity was evaluated on the 1st and 3rd days, and chronic toxicity on the 7th and 21st days after epidural injection of the study drugs. One examiner, who was unaware of the study groups, observed the motor and sensory deficits. To evaluate both motor and sensory deficits, the pinch-toe test was performed by applying pain in the hind sole of rats and observing the responses to avoid it [18-20]; thus, the hind sole 
was pinched with a pair of forceps (01-1155, Solco, Korea) for maximum 6 seconds and the test was repeated 3 times, at intervals of at least 5 minutes. Motor function was assessed using a previously devised scoring system $[18,21]$; grades were defined, as follows: grade 1 = normal gait, with no evidence of motor paresis; grade 2 = normal gait, with slight hind paw deformity, such as plantar flexion of toes; grade 3 = slight gait disturbance, with motor weakness and/or an inverted hind paw; and grade 4 = prominent limping gait, with a dropped hind paw. Animals scoring higher than grade 2 were considered to have motor deficit.

Following behavioral observation, spinal cords were harvested on days 1, 3, 7 and 21 after drug administration, from 5 rats of each group, for histological tests. Under sevoflurane general anesthesia delivered via facemask, euthanasia and fixation were simultaneously induced by transcardial perfusion with $4 \%$ paraformaldehyde solution, mixed with $0.1 \mathrm{M}$ phosphate buffer. Approximately $1 \mathrm{~cm}$ length of lumbar spinal cord (i.e. where the catheter tip was located) was harvested and fixed in $10 \%$ neutral formalin solution. According to conventional tissue sample preparation methods, the fixed tissues were made as paraffin blocks, and 4-5 $\mu \mathrm{m}$ thick sections were prepared for the slides. Primarily, Hematoxylineosin staining was performed to assess general histopathologic findings; then, four neurotoxicity categories were assessed, as previously reported: (1) vacuolization of the dorsal funiculus, (2) chromatolysis of the motor neuron in the ventral horn, (3) neuritis, and (4) meningeal inflammation [18,22-24]. Among them, the vacuolization of the dorsal funiculus was subdivided into 4 grades: grade $0=$ no vacuole, grade $1=$ vacuoles observed in less than $10 \%$ of the dorsal funiculus surface, grade $2=$ vacuoles observed in $10-50 \%$ of the surface, and grade 3 $=$ vacuoles observed in more than $50 \%$ of the surface. For further evaluation of myelin injury, Luxol fast blue staining was added. Next, the neurofilament immunochemical staining was performed for in-depth assessment of the degree of axonal injury. One pathologist, who did not know the group allocation, performed all histological evaluation.

Intergroup comparisons of the body weight were analyzed using one way ANOVA on ranks, followed by the Duncan test. In all groups, the Fisher's exact test and Bonferroni correction were performed to analyze the impairment of motor and sensory function and the histological tests. For all statistical analyses, the SPSS software version 13.0 (SPSS, Chicago, IL) was used, and a $P$ value $<0.05$ was considered as statistically significant.

\section{Results}

At first, 71 animals were enrolled in total; however, 8 rats died due to sudden respiratory arrest after lidocaine injection and 3 rats in group A expired before the completion of the study. Thus, our final data were obtained from 60 rats.

Any rats did not show abnormal behavior, such as aggressiveness, severe crying, or excited behaviors, after the administration of the study drugs.

At 21 days after drug injection, the rats in group A showed decreased mean body weight, compared to the other two groups (Table 1).

The rats in groups $\mathrm{P}$ and $\mathrm{N}$ showed normal avoiding responses for the pinch-toe test and motor function of grade 1 at all observation periods. However, in group A, $75 \%$ rats on the day 1 and $80 \%$ rats on the day 21 showed either insufficient or

Table 1. Changes in the Rat Body Weight after Epidural Drug Injection

\begin{tabular}{cccccc}
\hline $\begin{array}{c}\text { Day after epidural } \\
\text { drug injection }\end{array}$ & $\begin{array}{c}\text { Baseline } \\
(\mathrm{n}=20 / \text { group })\end{array}$ & $\begin{array}{c}\text { 1st day } \\
(\mathrm{n}=20 / \text { group })\end{array}$ & $\begin{array}{c}\text { 3rd day } \\
(\mathrm{n}=15 / \text { group })\end{array}$ & $\begin{array}{c}\text { 7th day } \\
(\mathrm{n}=10 / \text { group })\end{array}$ & $\begin{array}{c}21 \text { st day } \\
(\mathrm{n}=5 / \text { group })\end{array}$ \\
\hline Group N & $199.4 \pm 19.2$ & $200.6 \pm 22.9$ & $227.5 \pm 10.8$ & $272.0 \pm 7.3$ & $432.0 \pm 25.0$ \\
Group P & $200.3 \pm 17.3$ & $205.3 \pm 21.2$ & $230.3 \pm 15.7$ & $277.2 \pm 12.8$ & $440.2 \pm 21.0$ \\
Group A & $198.2 \pm 22.4$ & $202.0 \pm 24.0$ & $207.4 \pm 18.3$ & $250.8 \pm 14.3$ & $345.0 \pm 17.0^{*}$ \\
\hline
\end{tabular}

Values are expressed as mean \pm SD. Group N: epidural injection of $0.3 \mathrm{ml}$ of normal saline, Group P: epidural injection of $3 \mathrm{mg} / 0.3 \mathrm{ml}$ of pregabalin, and Group A: epidural injection of $0.3 \mathrm{ml}$ of $40 \%$ alcohol. $* \mathrm{P}<0.05$ : group A vs. group $\mathrm{N}$ and group $\mathrm{P}$.

Table 2. Evaluation of the Pinch-toe Test at Each Observation Point, after the Epidural Drug Injection

\begin{tabular}{cccc}
\hline $\begin{array}{c}\text { Day after epidural } \\
\text { drug injection }\end{array}$ & $\begin{array}{c}\text { 1st day } \\
(\mathrm{n}=20 \text { /group) }\end{array}$ & $\begin{array}{c}\text { 3rd day } \\
(\mathrm{n}=15 / \text { group })\end{array}$ & $\begin{array}{c}7 \text { th day } \\
(\mathrm{n}=10 / \text { group })\end{array}$ \\
\hline Group N & $0(0)$ & $0(0)$ & $0(0)$ \\
Group P & $0(0)$ & $0(0)$ & $0(0)$ \\
Group A & $15(75)^{*}$ & $13(87)^{*}$ & $0(0)$ \\
$4(80)^{*}$ & $9(90)^{*}$ \\
\hline
\end{tabular}

Values are expressed as number (\%) of rats, out of the total number, which showed abnormal response. Group N: epidural injection of 0.3 ml of normal saline, Group P: epidural injection of $3 \mathrm{mg} / 0.3 \mathrm{ml}$ of pregabalin, and Group A: epidural injection of $0.3 \mathrm{ml}$ of $40 \%$ alcohol. *P < 0.05 : group A vs. group $\mathrm{N}$ and group $\mathrm{P}$. 
Table 3. Evaluation of the Motor Function at Each Observation Point, after Epidural Drug Injection

\begin{tabular}{|c|c|c|c|c|c|}
\hline \multicolumn{2}{|c|}{ Day after epidural drug injection } & $\begin{array}{c}\text { 1st day } \\
\text { ( } \mathrm{n}=20 \text { /group) }\end{array}$ & $\begin{array}{c}\text { 3rd day } \\
(\mathrm{n}=15 \text { /group) }\end{array}$ & $\begin{array}{c}\text { 7th day } \\
\text { (n=10/group) }\end{array}$ & $\begin{array}{c}\text { 21st day } \\
\text { (n=5/group) }\end{array}$ \\
\hline \multirow[t]{2}{*}{ Group N } & G1 & $20(100)$ & $15(100)$ & $10(100)$ & $5(100)$ \\
\hline & $\mathrm{G} 2-4$ & $0(0)$ & $0(0)$ & $0(0)$ & $0(0)$ \\
\hline \multirow[t]{2}{*}{ Group P } & G1 & $20(100)$ & $15(100)$ & $10(100)$ & $5(100)$ \\
\hline & $\mathrm{G} 2-4$ & $0(0)$ & $0(0)$ & $0(0)$ & $0(0)$ \\
\hline \multirow[t]{2}{*}{ Group A } & G1 & $0(0)$ & $0(0)$ & $0(0)$ & $0(0)$ \\
\hline & $\mathrm{G} 2-4$ & $20(100) *$ & $15(100)^{*}$ & $10(100)^{*}$ & $5(100) *$ \\
\hline
\end{tabular}

Values are expressed as number (\%) of rats out of total. Group N: epidural injection of 0.3 ml of normal saline, Group P: epidural injection of 3 $\mathrm{mg} / 0.3 \mathrm{ml}$ of pregabalin, Group A: epidural injection of $0.3 \mathrm{ml}$ of $40 \%$ alcohol. G: grade of motor function, G1: normal gait, with no evidence of motor paresis; G2: normal gait, with slight hind paw deformity; G3: slight gait disturbance, with motor weakness and/or an inverted hind paw, and G4: prominent limping gait, with a dropped hind paw. $* \mathrm{P}<0.05$ : group A vs. group $\mathrm{N}$ and group $\mathrm{P}$.

Table 4. Neuropathological Findings of Spinal Cord and Surrounding Tissues under Microscopic Examination, after the Epidural Injection of Test Drugs

\begin{tabular}{|c|c|c|c|c|c|c|c|c|c|c|c|c|c|c|c|c|c|}
\hline & \multirow{3}{*}{ Group } & \multicolumn{16}{|c|}{ Grade } \\
\hline & & \multicolumn{4}{|c|}{1 st day ${ }^{\dagger}(n=5)$} & \multicolumn{4}{|c|}{$3 r d$ day $^{\dagger}(n=5)$} & \multicolumn{4}{|c|}{7 th day $^{\dagger}(\mathrm{n}=5)$} & \multicolumn{4}{|c|}{21 st day ${ }^{\dagger}(n=5)$} \\
\hline & & 0 & I & II & III & 0 & I & II & III & 0 & I & II & III & 0 & I & II & III \\
\hline \multirow[t]{3}{*}{ Vacuolation } & $\mathrm{N}$ & 5 & 0 & 0 & 0 & 5 & 0 & 0 & 0 & 5 & 0 & 0 & 0 & 4 & 1 & 0 & 0 \\
\hline & $\mathrm{P}$ & 5 & 0 & 0 & 0 & 5 & 0 & 0 & 0 & 4 & 1 & 0 & 0 & 4 & 1 & 0 & 0 \\
\hline & $A^{*}$ & 0 & 3 & 2 & 0 & 0 & 0 & 2 & 3 & 0 & 0 & 2 & 3 & 0 & 0 & 1 & 4 \\
\hline \multirow[t]{3}{*}{ Chromatolysis } & $\mathrm{N}$ & \multicolumn{4}{|c|}{0} & \multicolumn{4}{|c|}{0} & \multicolumn{4}{|c|}{0} & \multicolumn{4}{|c|}{0} \\
\hline & $\mathrm{P}$ & \multicolumn{4}{|c|}{0} & \multicolumn{4}{|c|}{0} & \multicolumn{4}{|c|}{0} & \multicolumn{4}{|c|}{0} \\
\hline & A & \multicolumn{4}{|c|}{0} & \multicolumn{4}{|c|}{0} & \multicolumn{4}{|c|}{0} & \multicolumn{4}{|c|}{0} \\
\hline \multirow[t]{3}{*}{ Neuritis } & $\mathrm{N}$ & \multicolumn{4}{|c|}{0} & \multicolumn{4}{|c|}{0} & \multicolumn{4}{|c|}{0} & \multicolumn{4}{|c|}{0} \\
\hline & $\mathrm{P}$ & \multicolumn{4}{|c|}{0} & \multicolumn{4}{|c|}{0} & \multicolumn{4}{|c|}{0} & \multicolumn{4}{|c|}{0} \\
\hline & A & \multicolumn{4}{|c|}{0} & \multicolumn{4}{|c|}{0} & \multicolumn{4}{|c|}{$3 *$} & \multicolumn{4}{|c|}{$3 *$} \\
\hline Meningeal inflammation & $\mathrm{N}$ & & & & & & & & & & & & & & & & \\
\hline & $\mathrm{P}$ & & & & & & & & & & & & & & & & \\
\hline & A & & & & & & & & & & & & & & & & \\
\hline
\end{tabular}

Values are expressed as number of positive rats out of the total. Group N: epidural injection of 0.3 ml of normal saline, Group P: epidural injection of $3 \mathrm{mg} / 0.3 \mathrm{ml}$ of pregabalin, and Group A: epidural injection of $0.3 \mathrm{ml}$ of $40 \%$ alcohol. The grade of the vacuolation was assessed with a four-point scale, 0: no vacuolation, I: $<10 \%$ area, II: $10-50 \%$ area, and III: $>50 \%$ area of the dorsal funiculus vacuolated. *P $<0.05$ : group A vs. group $\mathrm{N}$ and group $\mathrm{P} .{ }^{\dagger}$ Days after epidural drug injection.

no response for the pinch-toe test. In addition, at all observation times, all rats in group A showed gait abnormality and the hind limb deformity higher than grade 2 (Table 2 and 3 )

The results of histological neurotoxicity assessed by light microscope were, as follows; in the $\mathrm{N}$ and $\mathrm{P}$ groups, the structure was well maintained, and there was no region suggesting neurotoxicity with chromatolysis of motor ganglions, vacuolization of the dorsal funiculus higher than grade 2, neuritis, or meningeal inflammation. In contrast, in group A, vacuolization was observed in all tissues (Table 4, Fig. 1 and 2). Neurofilament staining was performed for further evaluation of some tissues with equivocal vacuolization on the H\&E stain; thus, in groups $\mathrm{N}$ and $\mathrm{P}$, the axon injury was very scanty on the neurofilament staining. In contrast, significant degeneration and loss of axons was observed in the tissues of group A, with vacuolization of not only grade $2-3$, but also grade 1 on the H\&E stain (Fig. 3). In addition, both meningeal inflammation and neuritis were observed in tissues from the rats in group A, which was not detected in either group $\mathrm{N}$ or $\mathrm{P}$ (Fig. 4 and 5).

\section{Discussion}

From our results, epidurally administered pregabalin did not cause any acute or chronic neurotoxicity in rats.

Dose and volume are essential factors for adequacy of toxicity study. Considering an epidural dose of $1 / 10-1 / 30$ of the oral dose, the maximal dose of epidural pregabalin in human is estimated at $20-60 \mathrm{mg}$. The applied dose in the present study could be regarded as the equivalent of $900 \mathrm{mg}$ in a $60 \mathrm{~kg}$ adult; therefore, our study dose was 15-45 times higher than the dose expected to be used in clinical practice. In addition, the maximal dose of oral pregabalin previously used in rats was 30 $\mathrm{mg} / \mathrm{kg}$ [25-27]. From this, the epidural dose of pregabalin in the rat was estimated at $1-3 \mathrm{mg} / \mathrm{kg}$. Taken together, the dose used in our experiment should be considered as sufficient for evaluation of neurotoxicity. In a previous study of epidural 

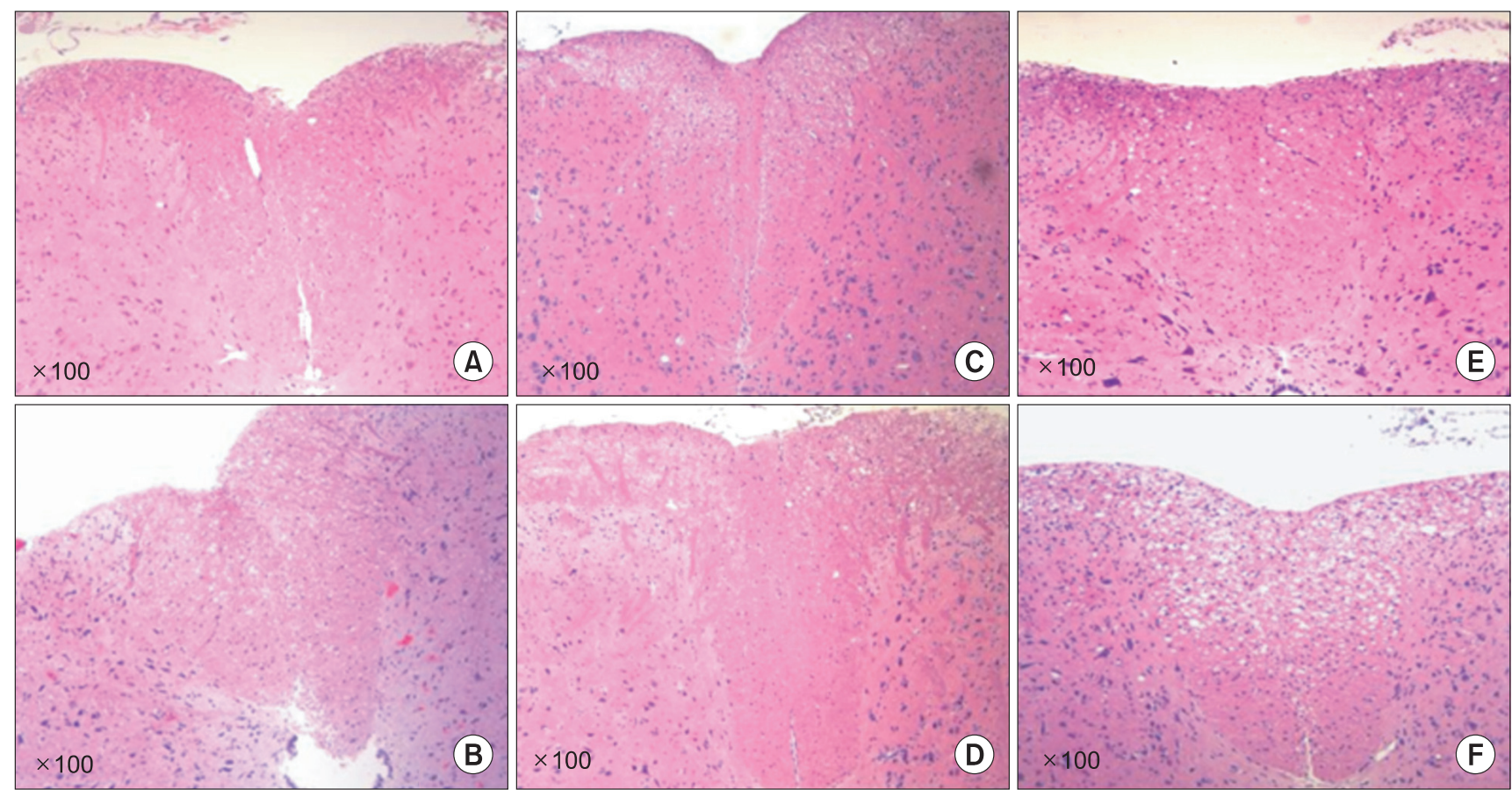

Fig. 1. The degree of vacuolization in the dorsal funiculus. (A, B) Epidural injection of $0.3 \mathrm{ml}$ of normal saline, (C, D) Epidural injection of 3 $\mathrm{mg} / 0.3 \mathrm{ml}$ of pregabalin, and (E, F) Epidural injection of $0.3 \mathrm{ml}$ of $40 \%$ alcohol. The pictures of (A-C) and (D) show no (A, C) or only mild (B, D) vacuolization. In contrast, the pictures of $(\mathrm{E})$ and $(\mathrm{F})$ show moderate and severe vacuolization, respectively. Hematoxylin and eosin stain.
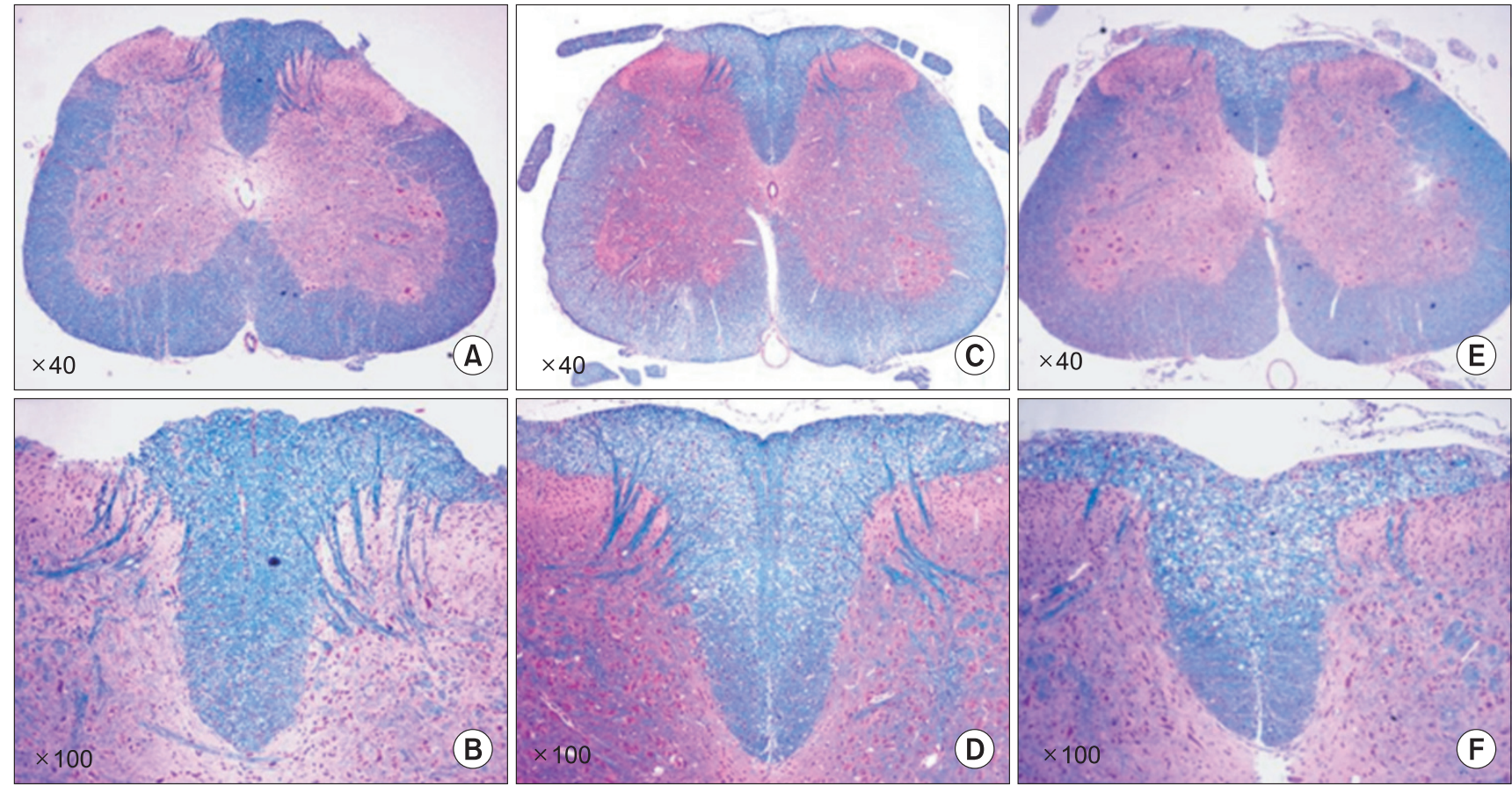

Fig. 2. The degree of myelin loss in the dorsal funiculus. (A, B) Epidural injection of $0.3 \mathrm{ml}$ of normal saline, (C, D) Epidural injection of $3 \mathrm{mg} / 0.3$ $\mathrm{ml}$ of pregabalin, and (E, F) Epidural injection of $0.3 \mathrm{ml}$ of $40 \%$ alcohol. The pictures of (A-C) and (D) show normal morphology of myelin. In contrast, the pictures of (E) and (F) show severe myelin loss, presented as vacuolization on the previous hematoxylin-eosin stain. Luxol fast blue stain. 

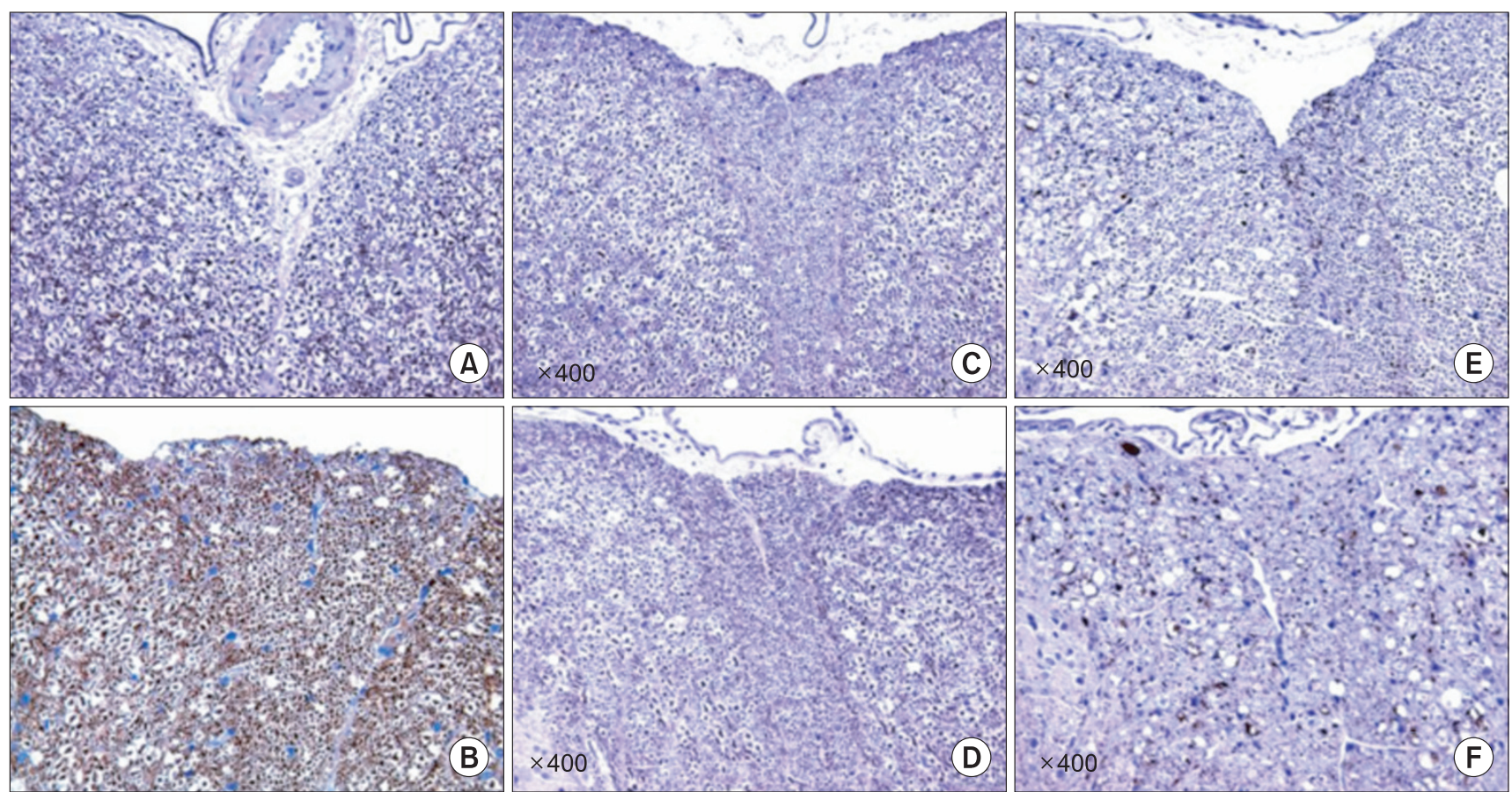

Fig. 3. The degree of axonal degeneration in the dorsal funiculus. (A, B) Epidural injection of $0.3 \mathrm{ml}$ of normal saline, (C, D) Epidural injection of $3 \mathrm{mg} / 0.3 \mathrm{ml}$ of pregabalin, and (E, F) Epidural injection of $0.3 \mathrm{ml}$ of $40 \%$ alcohol. The pictures of (A-C) and (D) show no significant axonal degeneration, although (B) and (D) showed mild vacuolization on the hematoxylin-eosin stain. In contrast, (E) and (F) show significant axonal degeneration, with moderate and severe vacuolization seen, respectively, on the hematoxylin-eosin stain. Immunohistochemical stain with neurofilament antibody.
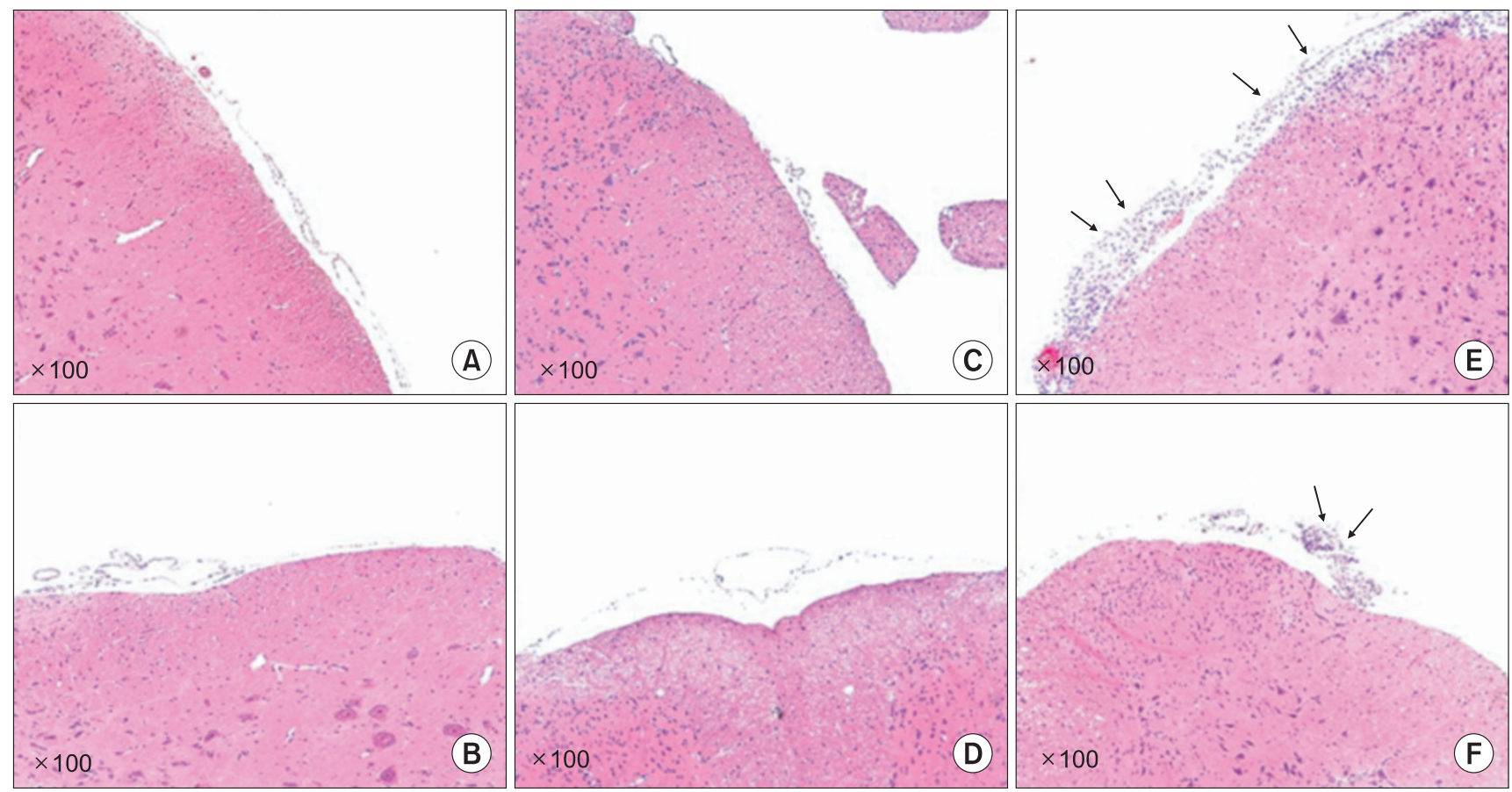

Fig. 4. The degree of meningeal inflammation. (A, B) Epidural injection of $0.3 \mathrm{ml}$ of normal saline, (C, D) Epidural injection of $3 \mathrm{mg} / 0.3 \mathrm{ml}$ of pregabalin, and (E, F) Epidural injection of $0.3 \mathrm{ml}$ of $40 \%$ alcohol. The meninges of (A-D) are thin and show no infiltration of inflammatory cells. In contrast, the meninges of (E) and (F) are thickened and show heavy infiltration of inflammatory cells, such as neutrophils (black arrow). Hematoxylin and eosin stain. 


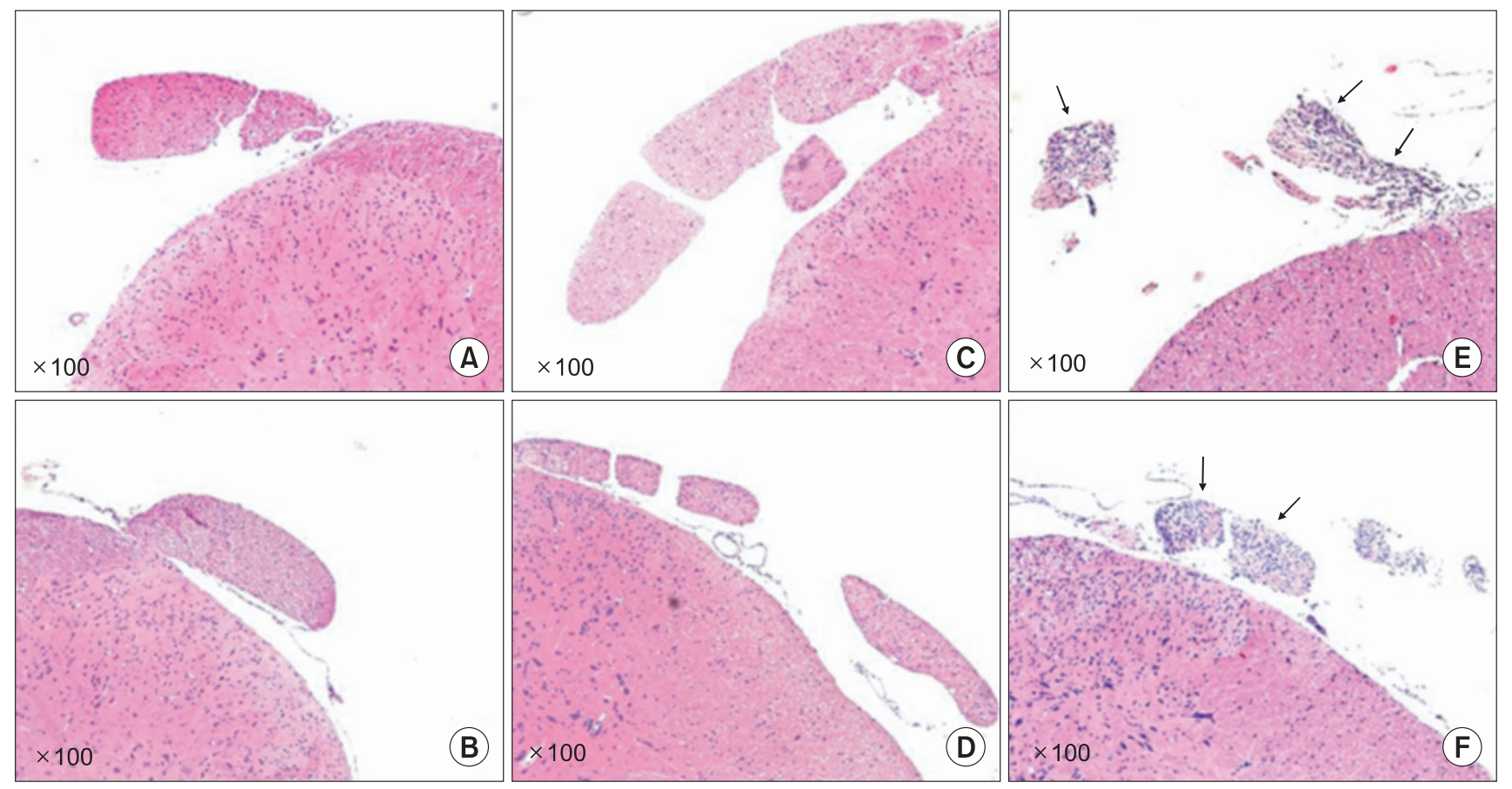

Fig. 5. Neuritis in the spinal neurons. (A, B) Epidural injection of $0.3 \mathrm{ml}$ of normal saline, (C, D) Epidural injection of $3 \mathrm{mg} / 0.3 \mathrm{ml}$ of pregabalin, and (E, F) Epidural injection of $0.3 \mathrm{ml}$ of $40 \%$ alcohol. In (A-D) there is no infiltration of inflammatory cells. In contrast, (E and F) show heavy infiltration of inflammatory cells, such as neurophils (black arrow). Hematoxylin and eosin stain.

gabapentin, the study dose was calculated from the intrathecal dose [18]. However, such data was unavailable in the case of pregabalin. In addition, the dose used in our study did not induce any systemic toxic symptoms. Therefore, we consider that additional dose adjustments of toxicity study would not be required.

The volume of drug should be also considered, because it is also essential in toxicity study. It has been shown that epidural administration of $0.1 \mathrm{ml}$ in rats is equivalent to administration of $10-15 \mathrm{ml}$ in humans [15]. Similarly, a volume of $0.3 \mathrm{ml}$ contrast medium was known to spread throughout the 10-11 segments of vertebra in rats; most other drugs would spread more widely, because they have lower viscosity than the contrast media [18]. In our study, the catheter tip was placed in the L1 area and 0.3 $\mathrm{ml}$ pregabalin was administered; thus, pregabalin could spread at least from the 9th thoracic vertebra to the 6th lumbar vertebra and it was sufficient to examine the motor and sensory changes in the hind limbs innervated by the $3^{\text {rd }}$ to the $6^{\text {th }}$ lumbar nerve roots. Additionally, it was suitable for obtaining spinal cord tissue from the L1 area, where the tip of the catheter was placed.

The pinch-toe test is a method to evaluate either the paralysis of hind limbs or the deterioration of nociperception in rodent study. The grade system used in our study was also used in the neurotoxicity study of Choi et al. [18], as well as in the study from Bajrovic and Sketelj [20]. In addition, motor function was assessed by gait patterns and the deformity of hind limbs as previously described [21], but only grade 1 was considered as normal, in order to increase test sensitivity. Moreover, histological tests are essential, because most organs have sufficient ability to overcome the damaged function; consequently, observing only the behavioral pattern may underestimate neurotoxicity [28]. Histological findings associated with neurotoxicity could be classified as nerve damage, gliosis, loss of myelin, and inflammation in the adjacent tissues [29]. Therefore, in our study, chromatolysis of motor nerve ganglions, vacuolization of the dorsal funiculus, and neuritis associated with abnormal infiltration of lymphocytes were assessed to determine the nerve damage, myelin loss, and inflammation in the adjacent tissue, respectively. Group A exhibited all neurotoxicity findings. Although grade 1 vacuolization was observed in some cases of the $\mathrm{P}$ group on the days 7 and 21 after drug administration, this finding was also detected in group $\mathrm{N}$, which was the negative control group. Furthermore, on the neurofilament staining, the tissues with minimal vacuolization in groups $\mathrm{P}$ and $\mathrm{N}$ were similar to the normal tissues, but clearly distinguishable from group A. Therefore, we conclude that epidural administration of pregabalin did not induce nerve damage, as assessed both functionally and histologically.

Neuraxial administration includes subarachnoid and epidural administration. Epidural administration has the advantage of acting on nerve ganglions passing through 
the epidural space, hence the effect of the peripheral nerve block could be achieved simultaneously [8]. Therefore, it is a favored method in clinical practice. In the present study, the neurological safety of epidurally administered pregabalin was proven. However, it is controversial to extrapolate the results to the safety of the intrathecal administration. Moreover, in this study, a high dose of pregabalin was administered as a single dose, and thus it may not concur to the results of chronic epidural injection.

Prior to clinical application, assessment of neurotoxicity of drugs in animal species which are closer to humans is recommended $[13,14]$. Therefore, based on our study, additional studies should be conducted to confirm safety at the standard at which it could be directly applied in clinical practice.

In conclusion, when pregabalin at $15 \mathrm{mg} / \mathrm{kg}$ dose was administered to the epidural space of rats, we found no neurotoxic effects, assessed by both behavior observation and pathohistological examination. If the results of the neurological safety of pregabalin are proven in other animal species in the future, the epidural administration of pregabalin may improve treatment effectiveness.

\section{Acknowledgements}

We wish to thank the manufacturer, Pfizer, for providing pregabalin as white crystalline powder without any additives (request No \#43892).

This work was supported by Seoul National University College of Medicine Research Fund, No 3420060500.

\section{References}

1. Dworkin RH, Corbin AE, Young JP Jr, Sharma U, LaMoreaux L, Bockbrader H, et al. Pregabalin for the treatment of postherpetic neuralgia: a randomized, placebo-controlled trial. Neurology 2003; 60: 1274-83.

2. Rosenstock J, Tuchman M, LaMoreaux L, Sharma U. Pregabalin for the treatment of painful diabetic peripheral neuropathy: a doubleblind, placebo-controlled trial. Pain 2004; 110: 628-38.

3. Shneker BF, McAuley JW. Pregabalin: a new neuromodulator with broad therapeutic indications. Ann Pharmacother 2005; 39: 202937.

4. Gribkoff VK. The role of voltage-gated calcium channels in pain and nociception. Semin Cell Dev Biol 2006; 17: 555-64.

5. Maneuf YP, Luo ZD, Lee K. Alpha-2-delta and the mechanism of action of gabapentin in the treatment of pain. Semin Cell Dev Biol 2006; 17: 565-70.

6. Yaksh TL. Calcium channels as therapeutic targets in neuropathic pain. J Pain 2006; Supp1: S13-30.

7. Sills GJ. The mechanisms of action of gabapentin and pregabalin. Curr Opin Pharmacol 2006; 6: 108-13.

8. Schug SA, Saunders D, Kurowski I, Peach MJ. Neuraxial drug administration: a review of treatment options for anaesthesia and analgesia. CNS Drugs 2006; 20: 917-33.

9. Kaneko M, Mestre C, Sánchez EH, Hammond DL. Intrathecally administered gabapentin inhibits formalin-evoked nociception and the expression of Fos-like immunoreactivity in the spinal cord of the rat. J Pharmacol Exp Ther 2000; 292: 743-51.

10. Yoon MH, Choi JI, Jeong SW. Spinal gabapentin and antinociception: mechanism of action. J Korean Med Sci 2003; 18: 255-61.

11. Chen SR, Pan HL. Effect of systemic and intrathecal gabapentin on allodynia in a new rat model of postherpetic neuralgia. Brain Res 2005; 1042: 108-13.

12. Cheng JK, Chen CC, Yang JR, Chiou LC. The antiallodynic action target of intrathecal gabapentin: Ca2+ channels, KATP channels or N-Methyl-D-Aspartic acid receptors? Anesth Anlag 2006; 102: 182-7.

13. Yaksh TL, Collins JG. Studies in animal should precede human use of spinally administered drugs. Anesthesiology 1989; 70: 4-6.

14. Hassenbusch SJ, Portenoy RK, Cousins M, Buchser E, Deer TR, Du Pen SL, et al. Polyanalgesic consensus conferences 2003: an update on the management of pain by intraspinal drug delivery-report of an expert panel. J Pain Symptom Manage 2004; 27: 540-63.

15. Hayashi N, Weinstein JN, Meller ST, Lee HM, Spratt KF, Gebhart GF. The effect of epidural injection of betamethasone or bupivacaine in a rat model of lumbar radiculopathy. Spine (Phila Pa 1976) 1998; 23 : 877-85.

16. Kim YC, Lim YJ, Lee SC. Spreading pattern of epidurally administrated contrast media in rabbits. Acta Anaesthesiol Scand 1998; 42: 1092-5.

17. Kawakami M, Matsumoto T, Hashizume H, Kuribayashi K, Tamaki T. Epidural injection of cyclooxygenase-2 inhibitor attenuates painrelated behavior following application of nucleus pulposus to the nerve root in the rat. J Orthop Res 2002; 20: 376-81.

18. Choi SS, Kim YC, Lim YJ, Lee CJ, Lee PB, Lee SC, et al. The neurological safety of epidural gabapentin in rats: a light microscopic examination. Anesth Analg 2005; 101: 1422-6.

19. Thalhammer JG, Vladimirova M, Bershadsky B, Strichartz GR. Neurologic evaluation of the rat during sciatic nerve block with lidocaine. Anesthesiology 1995; 82: 1013-25.

20. Bajrović F, Sketelj J. Extent of nociceptive dermatomes in adult rats is not primarily maintained by axonal competition. Exp Neurol 1998; 150: 115-21.

21. Kawakami M, Weinstein JN, Spratt KF, Chatani K, Traub RJ, Meller ST, et al. Experimental lumbar radiculopathy. Immunohistochemical and quantitative demonstrations of pain induced by lumbar nerve root ligation of the rat. Spine (Phila Pa 1976) 1994; 19: 1780-94.

22. Madsen JB, Jensen FM, Faber T, Bille-Hansen V. Chronic catheterization of the epidural space in rabbits: a model for behavioral and histopathological studies: examination of meptzsinol neurotoxicity. Acta Anaesthesiol Scand 1993; 37: 307-13.

23. Gurun MS, Leinbach R, Moore L, Lee CS, Owen MD, Eisenach JC. Studies on the safety of glucose and paraben-containing neostigmine for intrathecal administration. Anesth Analg 1997; 85: 317-23.

24. Lim YJ, Sim WS, Kim YC, Lee SC, Choi YL. The neurotoxicity of epidural hyaluronic acid in rabbits: a light and electron microscopic examination. Anesth Analg 2003; 97: 1716-20. 
25. Field MJ, McCleary S, Hughes J, Singh L. Gabapentin and pregabalin, but not morphine and amitriptyline, block both static and dynamic components of mechanical allodynia induced by streptozocin in the rat. Pain 1999; 80: 391-8.

26. Eutamene H, Coelho AM, Theodorou V, Toulouse M, Chovet M, Doherty A, et al. Antinociceptive effect of pregabalin in septic shock-induced rectal hypersensitivity in rats. J Pharmacol Exp Ther 2000; 295: 162-7.
27. Chen SR, Xu Z, Pan HL. Stereospecific effect of pregabalin on ectopic afferent discharges and neuropathic pain induced by sciatic nerve ligation in rats. Anesthesiology 2001; 95: 1473-9.

28. Norton $\mathrm{S}$. Is behavior or morphology a more sensitive indicator of central nervous system toxicity? Environ Health Perspect 1978; 26 : 21-7.

29. Hodgson PS, Neal JM, Pollock JE, Liu SS. The neurotoxicity of drugs given intrathecally. Anesth Analg 1999; 88: 797-809. 